\title{
An Airborne Campaign Measuring Wind Signatures from the Sea Surface using an L- band Polarimetric Radiometer
}

\author{
Søbjærg, Sten Schmidl; Skou, Niels
}

Published in:

IGARRS 2003 Proceedings of IEEE International Geoscience and Remote Sensing Symp, Toulouse, France

Link to article, DOI:

10.1109/IGARSS.2003.1294569

Publication date:

2003

Document Version

Publisher's PDF, also known as Version of record

Link back to DTU Orbit

Citation (APA):

Søbjærg, S. S., \& Skou, N. (2003). An Airborne Campaign Measuring Wind Signatures from the Sea Surface using an L-band Polarimetric Radiometer. In IGARRS 2003 Proceedings of IEEE International Geoscience and Remote Sensing Symp, Toulouse, France (pp. 2738-2740). IEEE.

https://doi.org/10.1109/IGARSS.2003.1294569

\section{General rights}

Copyright and moral rights for the publications made accessible in the public portal are retained by the authors and/or other copyright owners and it is a condition of accessing publications that users recognise and abide by the legal requirements associated with these rights.

- Users may download and print one copy of any publication from the public portal for the purpose of private study or research.

- You may not further distribute the material or use it for any profit-making activity or commercial gain

- You may freely distribute the URL identifying the publication in the public portal 


\title{
An Airborne Campaign Measuring Wind Signatures from the Sea Surface using an L-band Polarimetric Radiometer
}

\author{
Sten Schmidl Søbjærg \& Niels Skou \\ Ørsted-DTU, Electromagnetic Systems, Building 348 \\ Technical University of Denmark \\ DK 2800 Kongens Lyngby, Denmark \\ E-mail: sss@oersted.dtu.dk
}

\begin{abstract}
A series of circle flights have been carried out over the sea surface, using the EMIRAD L-band polarimetric radiometer. Motion compensation is applied, and polarimetric azimuth signatures are generated. Single tracks show geophysical noise, typically about $2 \mathrm{~K}$, but averaging decreases the noise, producing signatures with variations below $500 \mathrm{mK}$. A harmonic analysis of the results provides no clear signature, and for the $2^{\text {nd }}, 3^{\text {rd }}$, and $4^{\text {th }}$ Stokes parameters it is shown, that a significant part of the signal must be due to Gaussian noise. The $1^{\text {st }}$ Stokes parameter is shown to have a $500 \mathrm{mK} 2^{\text {nd }}$ harmonic, but a comparison of the signature to the downwelling galactic background radiation indicates, that the signature may not origin from the wind driven sea surface pattern.
\end{abstract}

\section{INTRODUCTION}

A high-resolution L-band $(1.4 \mathrm{GHz})$ radiometer system, based on interferometric techniques, and known under the acronym SMOS (soil moisture ocean salinity), is under phaseB studies as one of ESA's Earth Explorer Opportunity Missions. Measuring the L-band brightness temperature over the oceans enables a determination of sea salinity. At best (open ocean with high salinity) the brightness sensitivity to salinity is $\Delta \mathrm{TB} / \Delta \mathrm{S}=1 \mathrm{~K} / \mathrm{psu}$ (practical salinity unit), and salinity determination to a $0.1 \mathrm{psu}$ level thus requires radiometric measurements to better than $0.1 \mathrm{~K}$.

Knowledge concerning the influence from other effects to at least the same level is necessary, and for the sea surface temperature, the requirement is realistic, as the effects are well understood, and as the temperature is well monitored by other sensors. The knowledge about the influence from the wind is identified as insufficient, however, and no polarimetric signatures - i.e. the brightness temperature dependence on azimuth viewing angle - exist. This paper will discuss some of the results from the airborne campaign, LOSAC (L-band Ocean Salinity Airborne Campaign) aiming at identification of eventual azimuth signatures and determination of their magnitude.

\section{THE EXPERIMENTS}

Four flights have been carried out over Danish waters during the campaign, one of them being a technical test flight. The EMIRAD L-band radiometer [1] has been used for all flights, providing simultaneous measurement of the full Stokes vector with a relative accuracy of $100 \mathrm{mK}$ for $1 \mathrm{~s}$ observation. The absolute calibration of the radiometer is within a few Kelvin, which is sufficient for the desired measurements. The radiometer uses a $2 \mathrm{~m}$ horn with a beam width of 15 degrees, providing a $400 \mathrm{~m}$ by $500 \mathrm{~m}$ footprint at $1000 \mathrm{~m}$ flight altitude. The complete setup is mounted side-looking in a C-130 aircraft.

A circle flight pattern was selected for the measurements, as data acquisition at a range of incedence angles may be achieved by simply changing the aircraft roll. With a selected antenna depression angle of $d=23$ degrees, (1) gives the expected incidence angle, $\alpha$, for the aircraft roll, $\phi$.

$$
\alpha=90^{\circ}-d-\phi
$$

Incidence angles from 22 degrees to 62 degrees were covered, measuring minimum three circles of each incidence on each mission. Flights were carried out at wind speeds from $3.6 \mathrm{~m} / \mathrm{s}$ to $11.0 \mathrm{~m} / \mathrm{s}$, and for the highest wind speed, measurements were done at three different flight altitudes to investigate the effect of different spatial integration.

\section{AIRCRAFT MOTION COMPENSATION}

Pitch and roll variations are measured continuously during the flights using an INU (Inertial Navigation Unit), mounted directly on the aircraft floor, giving the full aircraft attitude with a precision of 0.1 degree. With the INU data the radiometer data can be corrected, and signatures can be calculated. The radiometer data dependence on the attitude parameters can be regarded as a combination of the antenna vector rotation, causing polarization mixing, and small changes of the incidence angle. Finally the data must be correctly aligned to the observation angle, relative to the fixed Earth coordinate system. All these angles may be derived directly from the measured aircraft attitude. 
The antenna vector rotation depends only on the aircraft pitch, $\theta$. The measured Stokes vector as a function of the true Stokes vector and the rotation angle is given by (2).

$$
\underline{T_{B}^{\prime}}=\left(\begin{array}{c}
I^{\prime} \\
Q^{\prime} \\
U^{\prime} \\
V^{\prime}
\end{array}\right)=\left(\begin{array}{cccc}
1 & 0 & 0 & 0 \\
0 & \cos (2 \theta) & \sin (2 \theta) & 0 \\
0 & -\sin (2 \theta) & \cos (2 \theta) & 0 \\
0 & 0 & 0 & 1
\end{array}\right)\left(\begin{array}{c}
I \\
Q \\
U \\
V
\end{array}\right)=\left(\begin{array}{c}
I \\
Q^{*} \cos (2 \theta)+U \sin (2 \theta) \\
-Q^{*} \sin (2 \theta)+U \cos (2 \theta) \\
V
\end{array}\right)
$$

The incidence angle, $\alpha$, depends on the aircraft pitch, $\theta$, roll, $\phi$, and antenna depression angle, d, and (3) shows the relation.

$$
\cos (\alpha)=\cos (\theta) \sin (\phi+d)=\cos (\theta) \cos \left(\phi+d-90^{\circ}\right)
$$

For the actual incidence angle, $\alpha$, the expected brightness temperature deviation, $\delta \mathrm{T}$, is given by (4), where $\mathrm{T}(\alpha)$ is the measured brightness for the actual incidence angle, and $\mathrm{T}\left(\alpha_{0}\right)$ is the expected brightness temperature for the nominal incidence angle, $\alpha_{0}$.

$$
\delta T=T(\alpha)-T\left(\alpha_{0}\right)
$$

Using a model for the expected sea surface brightness temperature, (4) may be calculated and subtracted from the measured radiometer data for each point of observation. To investigate the sensitivity to the choice of model, two different models were used for comparison. The $1^{\text {st }}$ model applied was the Klein-Swift model [2], directly applied to (4). The $2^{\text {nd }}$ model was created from real data, as a large-scale roll variation ( 0 degrees to 45 degrees) was carried out prior to the data collection. Low-pass filtering of the acquired curve thus provided an alternative model, taking into account the actual radiometer calibration, the sea conditions, etc.

Comparison of the two methods shows very similar results, and it must be concluded, that the model choice is of minor importance, and for both models residual errors of less than $100 \mathrm{mK} /$ degree were found. With typical variations within a circle track less than 1 degree, both models thus may be used for the correction.

\section{EXPERIMENT RESULTS}

The data analysis is focussed on the data from the flight with $11.0 \mathrm{~m} / \mathrm{s}$ wind speed, as the high wind is expected to present the clearest azimuth signature - if present. The corrected signatures typically have up to $2 \mathrm{~K}$ variations within one circle in the $1^{\text {st }}$ and $2^{\text {nd }}$ Stokes parameters and up to $1 \mathrm{~K}$ in the $3^{\text {rd }}$ and $4^{\text {th }}$ Stokes parameters. In some cases azimuth signals seem stable over 2 circles, but then disappear in a third. Harmonic analysis of the signatures indicates no systematic results, and it must be concluded, that a significant component of geophysical noise is present.

As three circles of each incidence angle is measured, however, averaging of subsequent tracks can be used to reduce the noise. Likewise an increment of the flight altitude may provide better spatial integration, and three circles, all with 45 degrees incidence angle, were obtained in each of the altitudes $1000 \mathrm{~m}, 2000 \mathrm{~m}$, and $3000 \mathrm{~m}$, in order to investigate the effect. The full polarimetric signatures for the three altitudes, each calculated as an average of three circles, are shown in fig.1-3, and no systematic signature seems to be present. The total root-mean-square (rms.) signal changes very little between the three cases, and no systematic noise reduction can be proven. For all altitudes the rms. noise is about $400 \mathrm{mK}$ for the $1^{\text {st }}$ Stokes parameter, $300 \mathrm{mK}$ for the $2^{\text {nd }}$, and about $200 \mathrm{mK}$ for the $3^{\text {rd }}$ and $4^{\text {th }}$ Stokes parameters after averaging.
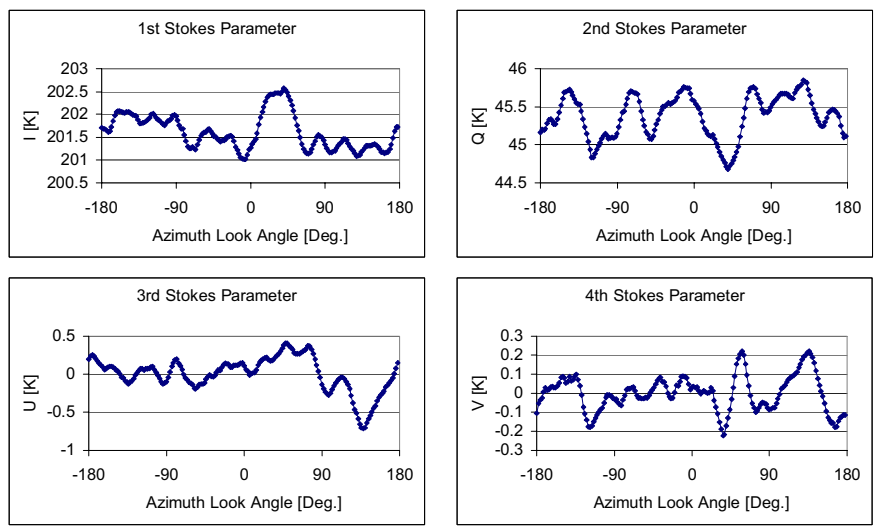

Figure 1. The averaged four Stokes parameters from the circle flight tracks with $45^{\circ}$ incidence angle and $1000 \mathrm{~m}$ flight altitude.
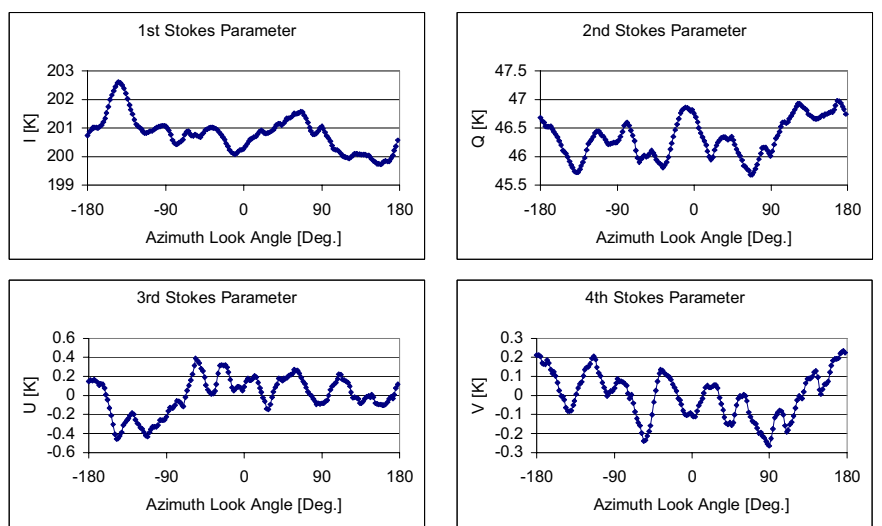

Figure 2. The averaged four Stokes parameters from the circle flight tracks with 45 incidence angle and $2000 \mathrm{~m}$ flight altitude.
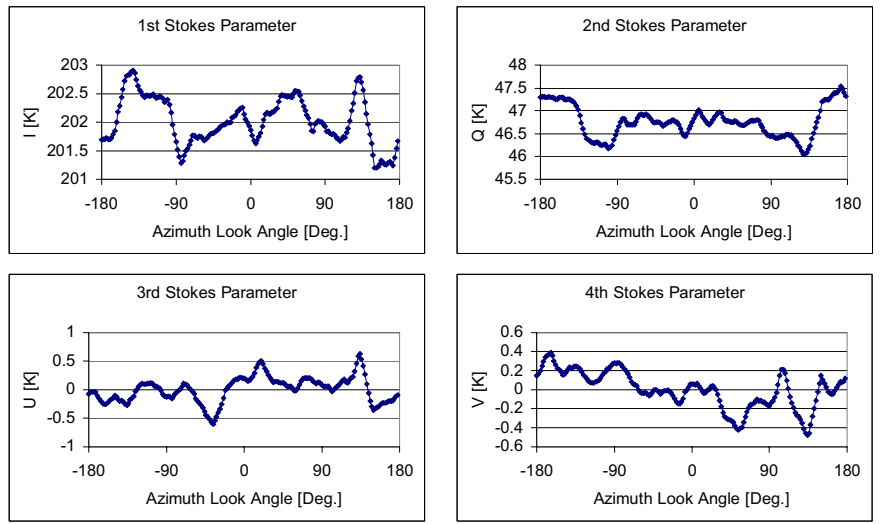

Figure 3. The averaged four Stokes parameters from the circle flight tracks with $45^{\circ}$ incidence angle and $3000 \mathrm{~m}$ flight altitude. 
As the effect of better spatial integration proves to be very small, the next step is to investigate the effect of temporal integration, regarding all nine circles as samples of identical conditions. The root-mean-square noise is calculated for single circles, for the circles averaged for each altitude, and finally as an average of all nine. The harmonic signature, resulting from the full integration of all circles with 45 degrees incidence angle, is shown in fig.4.

The result proves to be very clear for the $2^{\text {nd }}$, the $3^{\text {rd }}$, and the $4^{\text {th }}$ Stokes parameters, as the rms. signal reduction for each step of integration is almost equal to $1 / \operatorname{sqrt}(3)$ within a few percent. The result indicates a significant amount of Gaussian noise, and calculations show, that even a small harmonic signal with an amplitude of $100 \mathrm{mK}$ would have reduced the integration efficiency by $15 \%$. For the $1^{\text {st }}$ Stokes parameter, however, the noise reduction is smaller, and the effect of integration turns out to be only about $50 \%$ of the expected value, indicating the presence of some permanent signal.

The presence of a permanent signal in the $1^{\text {st }}$ Stokes parameter is confirmed by calculation of a harmonic analysis from the integrated signature. For the $2^{\text {nd }}$, the $3^{\text {rd }}$, and the $4^{\text {th }}$ Stokes parameters, harmonic components turn out to be below $100 \mathrm{mK}$, except a $170 \mathrm{mK} 2^{\text {nd }}$ harmonic of the $2^{\text {nd }}$ Stokes parameter. For the $1^{\text {st }}$ Stokes parameter, however, a $1^{\text {st }}$ harmonic of $150 \mathrm{mK}$ is found, and a clear $490 \mathrm{mK} 2^{\text {nd }}$ harmonic, which is easily identified in fig.4, appears.

The identified signature is seen to appear primarily in the $1^{\text {st }}$ Stokes parameter and partly in the $2^{\text {nd }}$. A manmade noise signal would typically be fully polarized, resulting in a clear presence in the $1^{\text {st }}$ Stokes parameter, but also fully appearing in one or in some of the other Stokes parameters. As this pattern does not comply fully with the nature of the identified signal, the effect of known natural sources, which are typically unpolarized, must be considered. The Sun, which is a strong emitter at L-band could result in a signal up to $50 \mathrm{~K}$, but the flight was conducted after sunset to avoid this error. The Moon is not a strong emitter, and its presence would result in a maximum signal of the order of $150 \mathrm{mK}$. Other sources, e.g. the galactic center, could be interesting, however, and the azimuth signature for the downwelling radiation is presented in fig. 5 .
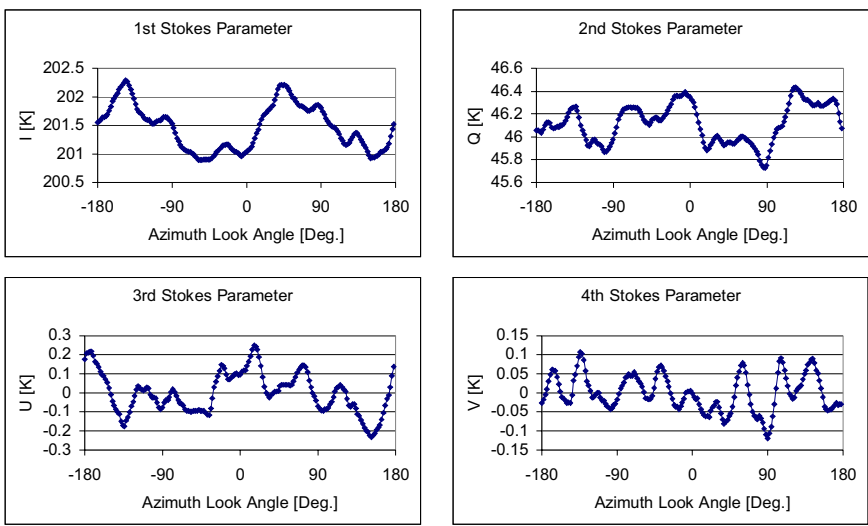

Figure 4. The averaged four Stokes parameters from all circle flight tracks with $45^{\circ}$ incidence angle.

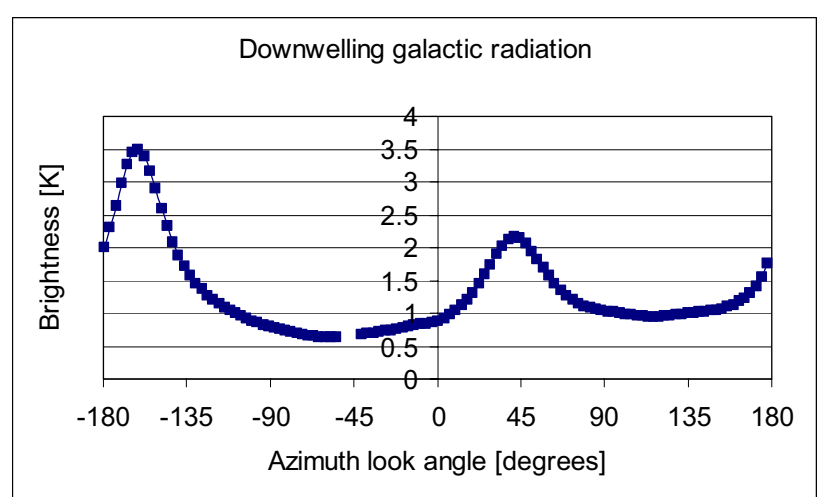

Figure 5. Downwelling radiation from the galactic background as a function of the azimuth look angle.

A clear correlation seems to exist, and the fractions of reflected signal in the two polarizations can be subtracted from the measured signature. It must be observed, however, that the correlation with the galactic background is much higher for vertical polarization than for horizontal, indicating that the reflection mechanism at the sea surface is a critical parameter. It should also be observed, that the total data acquisition for the circles takes about one hour, causing the background signal to move in azimuth. The circles must thus be corrected individually before averaging.

\section{CONCLUSION}

This paper has presented data from an airborne campaign, aiming at identification of eventual polarimetric azimuth signatures from the sea surface at L-band. Data from the flights have been motion compensated using two different correction models, but it must be concluded, that very similar signatures result, giving an estimated residual error of about $100 \mathrm{mK}$.

The individual signatures show peak-to-peak variations up to $1 \mathrm{~K}$, but averaging reduces the noise. It may thus be concluded, that less than $100 \mathrm{mK}$ signal is present in the $2^{\text {nd }}$, the $3^{\text {rd }}$, and the $4^{\text {th }}$ Stokes parameter. The $1^{\text {st }}$ Stokes parameter shows a $490 \mathrm{mK} 2^{\text {nd }}$ harmonic component, but it is illustrated that the signature is correlated with the downwelling galactic background. Individual corrections of the background radiation thus have to be subtracted from the measured signatures, and the reflection at the sea surface must be further investigated.

\section{ACKNOWLEDGMENT}

Thanks to Dr. David M. LeVine, Goddard Space Flight Center, NASA, for his valuable help with the calculation of the galactic background radiation on the test site.

\section{REFERENCES}

[1] J. Rotbøll, S.S. Søbjærg and N. Skou, "L-band polarimetric correlation radiometer with subharmonic sampling", Proceedings of the International Geoscience and Remote Sensing Symposium, IGARSS 2001, Vol. IV, pp1571 - 1574.

[2] L. A. Klein and C. T. Swift, "An improved model for the dielectric constant of sea water at microwave frequencies", IEEE Trans. Antennas and propagation, vol. AP-25, no. 1, January 1977, pp. 104-111. 